\title{
Representaciones sociales de la vocación docente
}

\author{
Social Representations of Teaching Vocation
}

\author{
Luciano Celis-Ibáñez'; Christian Sebastián-Balmaceda²
}

\begin{abstract}
RESUMEN
¿Qué es vocación docente? La presente investigación intenta caracterizar las representaciones sociales en torno a la vocación docente por parte de estudiantes de Pedagogía pertenecientes a una universidad tradicional chilena (2016-2017), reflexionando sobre la importancia, significado, origen y uso del concepto en las narrativas de dichos/as estudiantes. El estudio utiliza una metodología cualitativa no experimental, exploratoria y transversal, para caracterizar las representaciones sociales de los/as participantes, a través de la aplicación de un cuestionario en línea y la realización de grupos focales. Los principales hallazgos señalan que existe falta de claridad al momento de delimitar el significado de la vocación docente, atribuyéndole una propiedad de "entidad" a algo que no se logra describir con exactitud, pero que la mayoría de los/as participantes reconoce como un elemento importante en el desarrollo docente. Resulta interesante la forma en que dicho/as participantes caracterizan la vocación, reconociéndola como un factor dinámico en el tiempo y que se ve influido tanto por variables internas (motivación y expectativas) como externas (contexto laboral futuro, institución de formación docente y escenarios pedagógicos).
\end{abstract}

Palabras claves: vocación docente; formación docente; representaciones sociales; formación inicial docente; estudiantes de pedagogía.

\begin{abstract}
What is a teaching vocation? This research tries to characterize social representations around teaching vocation of students of Pedagogy belonging to a traditional Chilean university (2016-2017), reflecting on the importance, meaning, origin and use of the concept in the narratives of these students. The research uses a non-experimental, exploratory and transversal qualitative methodology to characterize the social representations of the participants, through the application of an online questionnaire and focus groups. The main findings indicate that there is a lack of clarity when delimiting the meaning of teaching vocation, attributing a property of "entity" to something that cannot be accurately described, but that most of the participants recognize as an important element in teacher development. It is interesting the way in which participants characterize the vocation, recognizing it as a dynamic factor over time and influenced both by internal (motivation and expectations) and external variables (future work context, teacher training institution and pedagogical scenarios)
\end{abstract}

\footnotetext{
${ }^{1}$ Encargado de Convivencia Escolar, Corporación de Desarrollo Social, Municipalidad de Providencia, Santiago, Chile; magíster en Psicología Educacional; lacelis@uc.cl.

${ }^{2}$ Director del Magíster en Psicología Educacional, Escuela de Psicología, Pontificia Universidad Católica de Chile, Santiago, Chile; doctor en Psicología; csebasti@uc.cl.
} 
Keywords: Teaching vocation; teacher training; social representations; initial teacher training; pedagogy students.

\section{Vocación docente}

Históricamente, el concepto de vocación docente ha sido asociado a diferentes formas según el significado que cada individuo le atribuye, sin embargo, estas significaciones han sido clasificadas en dos grandes concepciones que se presentan a continuación.

\section{Concepción teológica de vocación docente}

Para un grupo de autores como Zambrano (2014), Gracia (2007) y Larrosa (2010), el concepto de vocación docente es concebido como un "llamado y seguida" de una divinidad para educar, que surge de forma espontánea y que se manifiesta en algún momento determinado para guiar la vida de esa persona. También se relaciona con el "eros pedagógico" (Gracia, 2007), como una fuerza que moviliza a dar y recibir amor a través de la docencia. De esta forma, la vocación docente nacerá con el individuo y se mantendrá estable durante toda la vida, pero también se podría perder si se idealiza desmesuradamente la docencia (Marchesi y Díaz, 2007), en contraste con la realidad del trabajo profesional, generando problemas de agotamiento emocional que se describirán más adelante (Grund, Brassler y Fries, 2016). Paralelamente, de acuerdo a las teorías factorialistas propuestas por Parsons (1968, citado en González, 2003), la vocación docente que orienta a la elección profesional es un acto inconsciente para el individuo, porque es resultado de las aptitudes naturales del hombre y el rendimiento alcanzado en las pruebas estandarizadas psicológicas de orientación vocacional.

La vocación docente ha estado ligada a temas religiosos, políticos, sociales, ideológicos y económicos a lo largo de la historia como describe Larrosa (2010). En un periodo inicial, durante la Edad Media, dominó la idea de que una buena educación estaba determinada por docentes con una alta vocación, relacionada con la religión católica, siendo controlada por eclesiásticos. Posteriormente, la vocación docente se unió a la idea de un tipo de vida ejemplar, con moralidad 
REPRESENTACIONES SOCIALES DE LA VOCACIÓN DOCENTE / CELIS-IBÁÑEZ; SEBASTIÁN-BALMACEDA

irreprochable. Anteriormente, se le atribuyó un sentido de servicio a los demás y dedicación espiritual (Zambrano, 2014), que caracterizaba a un profesor sumiso, adaptativo y desinteresado por los bienes materiales.

De esta forma, Larrosa (2010) destaca que la vocación docente se caracteriza por el entusiasmo, la confianza y el compromiso con la educación, además de la dedicación especial al servicio para los demás. Al mismo tiempo, la considera un instrumento para controlar al que enseña, lo que enseña y la forma en la que procede en sus clases, así como también una herramienta para suplir carencias materiales y formales que son necesarias para el correcto desempeño profesional. De hecho, se podría hipotetizar que estas formas de concebir la vocación docente se relacionan con lo planteado por Dewck (1999) sobre la teoría de la inteligencia fija, donde el sujeto posee una noción fija y estable sobre sus habilidades y, en este caso, lo que es la vocación docente sería una cualidad que permanecería en el tiempo sin modificaciones o no permitiría la movilización hacia una transformación de la misma.

\section{Concepción experiencial de la vocación docente}

Otros autores como Fuentes (2001) y Altamira (1923, citado en Larrosa, 2010) conciben el concepto de vocación docente como un constructo experiencial del profesor a lo largo de su vida. Fuentes (2001) concibe a la vocación docente como una construcción de un proyecto existencial ideal frente al futuro laboral y profesional, o una expresión del desarrollo de la persona, como lo exponen las teorías evolucionistas (Super, 1968, citado en González, 2003), que surgiría dentro de un contexto sociocultural y escolar en el cual interaccionan los futuros docentes. Una cualidad que presenta esta concepción es que este proceso personal considera los siguientes indicadores: conocimiento del sujeto respecto al contenido de las profesiones preferidas, fundamentación de sus preferencias y autovaloración de sus posibilidades para ejercerlas. Altamira vinculó el concepto de vocación docente con la satisfacción que le produce al profesor el cumplir con las expectativas que tiene sobre su propio proyecto existencial, en torno al ejercicio docente (Altamira, 1923, citado en Larrosa, 2010), otorgando sentido al trabajo y a la vida personal de los educandos (Morgade, 2008). 
REVISTA SABERES EDUCATIVOS, Nº 5, JULIO-DICIEMBRE 2020

Para estos autores, la vocación docente se construiría en base a la experiencia y las expectativas que tiene el profesor en torno al desempeño docente, por lo que tendría un carácter dinámico y cambiante. Sin embargo, esta construcción estaría directamente relacionada con otro factor socioemocional como es la identidad profesional (Venegas, 2002), la cual se detalla a continuación.

\section{Identidad profesional}

La identidad profesional del profesor según diversos autores (Beijaard, 2004, Cattonar, 2001, Gohier, 2001, Vonck, 1995, citados en Vaillant, 2007), es un proceso dinámico e interactivo en permanente construcción, que unifica elementos de tipo subjetivos, como la historia personal, con elementos del tipo social, como referencias y pertenencias a un colectivo. La identidad profesional se realiza a lo largo de toda la vida del docente, en diferentes etapas personales, construyendo una imagen profesional que reúne dimensiones afectivas, cognitivas, personales y sociales en torno a una proyección del pasado al futuro (Vaillant, 2007), ligando el concepto de vocación docente con la dimensión afectiva (Ávalos, 2012).

En los inicios de la pedagogía, en la época medieval, la construcción social de la imagen del profesor se constituyó asociada a una función religiosa, al ser el clero el primer cuerpo docente, la cual exige una fuerte vocación o llamado interno para enseñar, implicando entrega y sacrificio del docente (Vaillant, 2007). Posteriormente, en la década de los sesenta, la identidad profesional docente se limitó más hacia una función técnica y profesional, ligada a componentes del conocimiento y la tecnología que maneja el profesor. De esta forma, se crean dos perspectivas para el concepto de identidad profesional docente: una en estrecha relación con la vocación docente desde la mirada religiosa, con una imagen de la profesión vinculada a la vocación, misión y sacrificio (Núñez, 20114 citado en Rodríguez \& Villalón, 2016), y otra referida al desempeño profesional o técnico del profesor, lo que para algunos autores (Follari, 1998; Hargreaves, 1999; Tenti, 2007, citados en Rodríguez y Villalón, 2016), implicaría el desarrollo técnico dentro del aula, pero a la vez un deterioro del status profesional docente, debido al aumento del control burocrático, la falta de apoyo institucional y la pérdida del carácter especializado y científico de la profesión, impactando en la identidad profesional de los docentes. 
REPRESENTACIONES SOCIALES DE LA VOCACIÓN DOCENTE / CELIS-IBÁÑEZ; SEBASTIÁN-BALMACEDA

De acuerdo a Venegas (2002), la identidad profesional se construye en base a la confianza que el/la futuro/a docente tiene para enfrentar las situaciones propias del aula, las herramientas con las cuales cuenta para su desempeño y la valoración que le otorga a su propio trabajo. Esto le permitirá desenvolverse de forma profesional y proactiva, impactando en el aprendizaje de sus estudiantes (Zembylas, 2005, citado en Marchesi y Díaz, 2007), pues, como plantea Bourgeois (2000, citado en Calderón, 2017), el sentido personal que las personas construyen al participar en la experiencia educativa (en este caso la formación docente), cumplirá una función de inteligibilidad, legitimación, orientación de acción y movilización, siendo un punto de articulación entre las dinámicas identitarias individuales, su proceso motivacional y su involucramiento afectivo en las acciones educativas (Marchesi y Díaz, 2007).

Desde un enfoque más amplio del desarrollo psicosocial de la identidad, como el que ofrece Hammack (2008), proponemos pensar el proceso de construcción de la identidad profesional como la internalización ${ }^{3}$ progresiva de la narrativa maestra del "ser profesor", la cual se reconstruye en cada individuo para construir una narrativa personal. Esta narrativa maestra materializa una ideología maestra, un conjunto más o menos organizado de creencias generales acerca de las características y posibilidades de acción de una sociedad y de los actores que se constituyen en ella (en el caso que nos concierne, los/as docentes). Dicho de otro modo, en el núcleo de las narrativas de identidad profesional encontramos un sistema de creencias que es sostenido por un grupo social más o menos amplio, es decir, un conjunto de representaciones sociales.

\section{Representaciones sociales sobre la vocación docente}

En directa relación con lo planteado en el párrafo anterior, proponemos entender las diferentes significaciones que cada individuo puede otorgarle al concepto de vocación docente en su narrativa individual como relativamente articuladas entre sí, en la medida que existiría un trasfondo que las sustenta y que sería parte de la mencionada “ideología maestra” (Hammack, 2008). En este sentido, proponemos entenderla aquí como una representación social (Duveen, 2007, citado en Carretero y Castorina, 2010). Duveen y Lloyd (2003, citados en Carretero y Castorina, 2010) explican que

\footnotetext{
${ }^{3}$ Usamos aquí el concepto vygotskiano de internalización, enfatizando su sentido de producción dialéctica (ÁlvarezEspinoza y Sebastián, 2018).
} 
las representaciones sociales aportarán los medios para comprender el mundo social desde una mirada psicológica (Carretero y Castorina, 2010), además de permitir a los individuos operar en base a un criterio colectivo común.

La génesis de la representación social es la interacción entre sujetos que necesitan responder problemas cotidianos. Dichas representaciones son utilizadas por los individuos dentro de las prácticas sociales de su grupo como acciones significativas, por el aporte al universo simbólico que representan (Carretero y Castorina, 2010). Surgen en espacios vacíos de significados que la cultura no logra explicar por su novedad, llevando a los grupos sociales a movilizar un proceso de habituación a lo desconocido, construyendo un significado para ese objeto o concepto (Moscocivi, 2001, citado en Carretero y Castorina, 2010). Esta construcción de significados se realizará mediante los procesos de objetivación y anclaje. La objetivación transforma los conocimientos de la cultura en imágenes o conceptos de la vida cotidiana a través de una selección, siempre relacionada con la narrativa maestra, naturalizándolos al otorgarle realidad o sentido al objeto. Por otro lado, la labor del anclaje es integrar esta representación creada a la red de conocimientos, valores y significados que operan en la misma cultura. En palabras de Jodelet (1985, citado en Carretero y Castorina, 2010, p.86), la construcción de la representación social por estos dos medios es la restitución simbólica de lo real.

Las representaciones sociales dependen de factores contingentes, vinculados con el contexto o situaciones sociales, y factores generales, como la ubicación del individuo en la organización social o la historia del grupo (Castorina, Barreiro y Clemente, 2005, citados en Carretero y Castorina, 2010, p.87). Esto no significa que existan representaciones más correctas o válidas que otras, ya que todas son una aproximación acertada a la realidad. Es así como los grupos y los individuos en este proceso de significación del mundo social van construyendo su identidad, al internalizar estas representaciones a sus estructuras previas para apropiarse de su entorno (Lloyd y Duveen, 2003, citado en Carretero y Castorina, 2010, p.87).

De esta forma, la presente investigación sostiene que existen representaciones sociales que sustentan las diferentes concepciones sobre la vocación docente (ya sea de forma teológica, experiencial o alguna concepción emergente), pero se hace necesario caracterizar cuáles serían esas representaciones que contribuyen a formar los conceptos de los profesores, realizando una aproximación a cómo los participantes de este estudio reconocen la vocación docente. 


\section{Metodología}

El objetivo general de este estudio es caracterizar las representaciones sociales de estudiantes de Pedagogía de una universidad tradicional chilena respecto a la vocación docente, describiendo dichas representaciones y determinando su valoración según la información analizada. El presente estudio utilizó un modelo metodológico cualitativo. El diseño de investigación fue no experimental y se caracterizaró por ser transversal.

La población analizada corresponde a estudiantes regulares de Pedagogía de una universidad tradicional chilena en los periodos 2016-2017, sin límite de edad. La muestra correspondió al tipo no probabilístico y estratificado. La estratificación se realizó en base al programa formativo: estudiantes de Pedagogía en Educación Básica y Pre-Básica con ingreso regular; estudiantes de Pedagogía en Educación Media con ingreso regular (Matemática y Ciencias Naturales con mención en Biología, Física y Química); estudiantes de Pedagogía pertenecientes al programa de admisión alternativo (donde ingresan con una licenciatura previa en una cierta disciplina y luego obtienen la Licenciatura en Pedagogía con una mención acorde a su carrera de origen).

Inicialmente se realizó un cuestionario virtual en base a cuatro preguntas abiertas: ¿Cuál es la importancia de la vocación docente?; ¿Qué es la vocación docente?; ¿De dónde surge la vocación docente?; ¿Qué utilidad tiene la vocación docente?). Dicho cuestionario fue respondido por 179 personas. Posteriomente se realizaron tres grupos focales, con 13 asistentes en total, participando entre 4 y 5 estudiantes por instancia. Los/as participantes de los grupos focales corresponden a voluntarios/as inscritos/as en el cuestionario virtual. En la realización de los distintos grupos focales se siguió la misma estructura de trabajo. 
REVISTA SABERES EDUCATIVOS, Nº 5, JULIO-DICIEMBRE 2020

\section{Tabla 1}

Estadísticas de participantes en la investigación

\begin{tabular}{|c|c|c|c|}
\hline & & Cuestionario online & Grupo focal \\
\hline \multicolumn{2}{|c|}{$\mathrm{N}^{\circ}$ de participantes } & 174 & 13 \\
\hline \multicolumn{2}{|c|}{ Edad promedio } & 22 años & 21 años \\
\hline \multirow{2}{*}{$\%$ Sexo de participantes } & Hombres & $18,4 \%$ & $15 \%$ \\
\hline & Mujeres & $81,6 \%$ & $85 \%$ \\
\hline \multirow{3}{*}{$\%$ Carreras participantes } & Grupo I & $74,9 \%$ & $53,8 \%$ \\
\hline & Grupo II & $12,3 \%$ & $23,1 \%$ \\
\hline & Grupo III & $12,8 \%$ & $23,1 \%$ \\
\hline \multirow{2}{*}{$\begin{array}{l}\text { \% Primera o segunda } \\
\text { carrera cursada }\end{array}$} & $1^{\mathrm{a}}$ carrera cursada & $60,3 \%$ & $76,9 \%$ \\
\hline & $2^{\text {a }}$ carrera cursada & $39,7 \%$ & $23,1 \%$ \\
\hline
\end{tabular}

Para el análsis de las respuestas obtenidas en el cuestionario online se aplicó un proceso de codificación abierta, el cual permitió obtener distintas categorías de respuestas, las que fueron agrupadas en tres macrocategorías, según se puede apreciar en el apartado de resultados. Posteriormente, se realizó una estrategia de codificación de la información, para analizar los datos obtenidos en los grupos focales mediante el enfoque de análisis del contenido, asumiendo las limitantes de este último. Finalmente, en las conclusiones se triangularon los resultados de ambos.

\section{Resultados del cuestionario}

\section{Importancia de la vocación docente}

Las respuestas abiertas respecto a la importancia de la vocación docente fueron codificadas en diferentes categorías, las cuales a su vez se organizaron en tres macrocategorías (Valoración tipo A, B y C). Estas últimas no representan necesariamente una graduación apreciativa lineal de la 
REPRESENTACIONES SOCIALES DE LA VOCACIÓN DOCENTE / CELIS-IBÁÑEZ; SEBASTIÁN-BALMACEDA

vocación docente, sino que agrupan diferentes aspectos de valoración que no pueden ser aglomerados bajo un título que posea un significado en sí mismo, pero que tienen en común la percepción expresada sobre la importancia de la vocación docente.

\section{VALORACIÓN TIPO A}

Cinco de las categorías construidas para clasificar las respuestas de los estudiantes comparten la característica de afirmar que la vocación docente es importante por considerar los siguientes elementos, los cuales son descritos brevemente y ejemplificados a continuación:

a) Evaluación docente. Para los estudiantes la vocación docente es importante para evaluar quién es un buen o mal docente, como indica la siguiente cita:

"Es lo más importante, ya que sin vocación y sin ganas de seguirla, no se puede ser un buen profesor. Debes querer más que a nada lo que haces, porque es una carrera muy importante y poco valorada, de ahí que es tan importante la vocación" (Participante 28).

b) Factor vocacional. La vocación docente es clave para poder determinar si se estudia una carrera relacionada con educación o no, destacando sobremanera cuando la persona se cambia desde otra carrera a Pedagogía, como se expresa en la siguiente cita: "En mi vida la vocación docente fue fundamental para decidir mi futuro, ya que me encontraba cursando otra carrera cuando me di cuenta que quería enseñar como profesión" (Participante 48).

c) Cambio social. La vocación docente sería importante para promover un cambio social. Es la forma de que se materialice: "Es una forma de mejorar la sociedad" (Participante 122).

d) Rol docente. La vocación docente sería una variable que destacaría en la vida de los docentes, siendo importante en la construcción de su identidad profesional al otorgar una característica única por sobre otras profesiones: "La vocación docente es muy determinante... Me hace sentir importante, por lo tanto, en mi vida, esta juega rol fundamental"' (Participante 47). 
REVISTA SABERES EDUCATIVOS, N 5, JULIO-DICIEMBRE 2020

e) Desarrollo individual. La vocación docente es presentada como importante al permitir el desarrollo individual de los docentes en torno a sus gustos, intereses y proyecciones personales: "Es la razón por la cual estudio esta carrera. Creo que la vocación permite la autorrealización de las personas" (Participante 84).

\section{VALORACIÓN TIPO B}

Las respuestas de los estudiantes agrupadas bajo esta categoría comparten la característica de afirmar que la vocación docente podría llegar a ser relevante o no, según las variables que en ella participan.

a) Una variable entre otras. La vocación docente es presentada como un factor no tan importante por sí solo, sería una de las variables que el docente debe considerar para ejercer su profesión: "Mediana, es decir, me gustaría trabajar en esto, pero depende de ciertas condiciones de justicia, en relación con la cantidad y calidad del trabajo que hago" (Participante 101).

\section{VALORACIÓN TIPO C}

Dos de las categorías construidas para clasificar las respuestas de los estudiantes comparten la característica de asignar una baja valoración a la noción de vocación docente. Dichas categorías son ejemplificadas a continuación:

a) Irrelevante. La vocación docente no es relevante para ser un profesional de la educación: "No es tan relevante. Creo que se puede ser buen profesional sin vocación" (Participante $18)$.

b) Sin vocación. Algunos encuestados indican que no poseen vocación docente: "No tengo vocación docente" (Participante 42). 


\section{Tabla 2}

Respuestas a la pregunta ¿Qué es la vocación docente?

\begin{tabular}{llcc}
\hline Macrocategorias & Categorías & Frecuencia & Porcentaje \\
\hline Valoración Tipo A & Evaluación docente & 5 & $3.8 \%$ \\
& Factor vocacional & 35 & $26,31 \%$ \\
& Cambio social & 21 & $15,79 \%$ \\
& Rol docente & 8 & $6 \%$ \\
Valoración Tipo B & Desarrollo individual & 52 & $39,1 \%$ \\
Valoración Tipo C & Variables & 5 & $3,8 \%$ \\
Total respuestas & & 5 & $3,8 \%$ \\
\hline & Sin vocación docente & 2 & $1,4 \%$ \\
& & $\mathbf{1 3 3}$ & $\mathbf{1 0 0 \%}$ \\
\hline
\end{tabular}

\section{¿Qué es la vocación docente?}

Estas respuestas abiertas se codificaron en dos macrocategorías: una que reconoce a la vocación docente como una entidad interna y movilizadora, y otra que la identifica como externa y movilizadora.

\section{ENTIDAD INTERNA Y MOVILIZADORA}

Cinco de las categorías construidas para clasificar las respuestas comparten la característica de otorgarle cualidades movilizadoras de carácter interno a la vocación docente. 
a) Manifestación a la sociedad. La vocación docente es entendida como una manifestación de amor hacia los demás, principalmente a las nuevas generaciones, representadas en los futuros estudiantes.

“La vocación docente es para mí un amor y pasión por la docencia que impulsa a uno a dar lo mejor para ser una buena profesional y, por ende, un aporte para los estudiantes y la sociedad que todos formamos" (Participante 11).

b) Sentido personal. La vocación docente es presentada como una conexión de cada docente con sus intereses personales, que le otorga un sentido a sus vidas. "Haciendo clases, disfrutar haciendo clases, me hace feliz enseñar a otros, le da sentido a mi vida" (Participante 23).

c) Gusto por educar. Para algunos, la vocación docente es un gusto por desempeñar labores educativas: "La vocación docente es el interés mismo, las ganas por enseñar, transmitir conocimientos y guiar o apoyar a otros a descubrir sus propios aprendizajes, es encaminar a otros en encontrar su propia vocación" (Participante 128).

d) Cambio social. La vocación docente se comprende como una forma de promover un cambio social, dentro de una sociedad que se percibe como injusta: "Un sentimiento, unas ganas de cambiar las cosas, mejorar las injusticias y algo que te mueve a aminorar las diferencias" (Participante 174).

e) Motor. La vocación docente es entendida como una fuerza que moviliza estudiar y ejercer la pedagogía: “Es el ‘motor’ que impulsa el perseguir esta carrera” (Participante 166).

\section{ENTIDAD EXTERNA Y MOVILIZADORA}

Tres de las categorías construidas para clasificar las respuestas comparten la característica de otorgarle cualidades movilizadoras de carácter externo a la vocación docente.

a) Reificación. La vocación docente sería una construcción de poder esclavizadora para los profesores: 
“De partida la 'vocación', como se conoce, no me parece realista, está restringida a una elite y creo que debería dejar de ser parte del discurso pedagógico. La vocación docente sería un deseo real por ser profesora, a pesar de todo" (Participante 169).

b) Llamado. La vocación docente es un llamado externo (divino, social, familiar, entre otros) a realizar una labor docente:

"Primero, la vocación, siento que es la razón por la que vino cada uno al mundo; y la vocación docente es para unos pocos que se sienten llamados a enseñar conocimientos tanto intelectuales como espirituales, que en un futuro les servirán para entenderse con la sociedad" (Participante 07).

c) Competencias docentes. La vocación docente es una cualidad que los docentes poseen para realizar su labor profesional, que agrupa habilidades propias del trabajo cotidiano: "Tener las competencias necesarias para ser profesora como paciencia, perseverancia, conciencia pedagógica, etcétera" (Participante 99).

\section{Tabla 3}

Respuestas a la pregunta ¿Qué es la vocación docente?

\begin{tabular}{lccc}
\hline Macrocategorias & Categorías & Frecuencia & Porcentaje \\
\hline Explicación interna y & Manifestación a la & 52 & $32,7 \%$ \\
movilizadora & sociedad & & \\
& Sentido personal & 20 & $12,6 \%$ \\
& Gusto por educar & 33 & $20,7 \%$ \\
& Cambio social & 13 & $8,2 \%$ \\
Explicación externa y & Motor & 18 & $11,3 \%$ \\
movilizadora & & & \\
& Reificación & 2 & $1,3 \%$ \\
Total respuestas & Llamado & 14 & $8,8 \%$ \\
\hline
\end{tabular}




\section{¿Cómo surge la vocación docente?}

Las respuestas a esta interrogante fueron codificadas en tres macrocategorías: una presenta el surgimiento de la vocación docente desde planteamientos asociacionistas, otra atribuye el origen a postulados constructivistas y, una tercera, desconoce el surgimiento de la vocación docente.

\section{SURGIMIENTO FIJO DE LA VOCACIÓN DOCENTE}

Dos de las categorías construidas comparten la característica de presentar un momento preciso en que se manifestó o que se logra reconocer la vocación docente, entendida como algo fijo que se reconoce como propio.

a) Experiencias significativas. Algunos/as encuestados/as mencionan que la vocación docente surge por medio de experiencias significativas en sus vidas:

"Yo creo que se va desarrollando con las experiencias con profesores, en mi caso mi profesora de primero y segundo básico fue la que me inspiró a ver la docencia como una posibilidad en mi vida y profesores que he tenido a lo largo de mi enseñanza escolar han fortalecido esa convicción" (Participante 02).

b) Sustancialismo. Algunos/as encuestados/as manifiestan que la vocación docente surgiría en las personas de forma natural y espontánea: “Creo que hay una 'chispita' con la que se viene" (Participante 30).

\section{SURGIMIENTO DE LA VOCACIÓN DOCENTE COMO UNA CONSTRUCCIÓN}

Tres de las categorías construidas comparten la característica de que la vocación sería un ente dinámico, sin existir un momento específico en la vida del profesor que señale el origen de la vocación docente. 
REPRESENTACIONES SOCIALES DE LA VOCACIÓN DOCENTE / CELIS-IBÁÑEZ; SEBASTIÁN-BALMACEDA

a) Interés social. Algunos/as encuestados/as indican que la vocación docente se construye por el interés de contribuir a la sociedad a través del desempeño docente, buscando un cambio social: "Parte de la crítica social y del deseo utópico de convertir la realidad en la que vivimos" (Participante 117).

b) Factores internos. La vocación docente surgiría de la manifestación de algunos factores internos:

"Creo que hay, como para todas las profesiones, intereses y talentos innatos a la persona. Pero, sin embargo, estos deben ser descubiertos y evidenciados por la persona, y para eso la sociedad y la educación misma debe abrir la opción a que todas las personas conozcan realmente lo que es la docencia, erradicar prejuicios y estereotipos y realzar la importancia de buenos educadores en un país" (Participante 147).

c) Procesos académicos. Algunos encuestados manifiestan que la vocación docente se aprende a través de los procesos académicos de los programas de formación docente: "Pienso que se desarrolla a lo largo de la carrera, una vez que ya conoces más o menos de qué se trata, antes son solo ilusiones de lo que será" (Participante 132).

\section{DESCONOCIMIENTO DE CÓMO SURGE LA VOCACIÓN DOCENTE}

Una de las categorías construidas para clasificar las respuestas de los estudiantes no logra explicar el origen de la vocación docente.

a) Desconocimiento. Un grupo de encuestados/as manifiesta no conocer de dónde surge la vocación docente: "No lo sé, realmente no sé de dónde viene” (Participante 28). 


\section{Tabla 4}

Respuestas a la pregunta ¿De dónde surge la vocación docente?

\begin{tabular}{lccc}
\hline \multicolumn{1}{c}{ Macrocategorias } & Categorías & Frecuencia & Porcentaje \\
\hline Surgimiento fijo de la vocación & Experiencias significativas. & 66 & $41,3 \%$ \\
docente & Sustancialismo & 23 & $14,3 \%$ \\
& & & \\
Surgimiento de la vocación & Interés social & 29 & $18,1 \%$ \\
docente como una construcción & Factores internos & 25 & $15,6 \%$ \\
& Procesos académicos & 11 & $6,9 \%$ \\
Desconocimiento & & & \\
Total respuestas & Desconocimiento & 6 & $\mathbf{1 0 0 \%}$ \\
\hline
\end{tabular}

\section{¿Qué utilidad tiene la vocación docente?}

En relación a las respuestas abiertas entregadas, estas fueron codificadas en 3 macrocategorías que incluyen a las categorías clasificadas según el tipo de respuesta que entregaron los encuestados, una que presenta la utilidad de la vocación docente en lo laboral, otra que la asocia a una utilidad personal y/o individual y una tercera que plantea que no tiene utilidad.

\section{UTILIDAD LABORAL DE LA VOCACIÓN DOCENTE}

Dos de las categorías construidas para clasificar las respuestas comparten la característica de asociar la utilidad de la vocación a un campo laboral.

a) Esclavitud laboral. Para algunos/as encuestados/as la vocación docente se utiliza para legitimar abusos laborales, explotación y enajenación de los docentes: 
"En estos momentos, creo que se ha viciado el concepto. De él se ha obtenido aprovechamiento para justificar el trabajo excesivo y el bajo pago monetario de los docentes. El mismo sistema no 'premia' a quienes trabajan por vocación, a quienes innovan, sino que todo continúa igual, por parte del ministerio y las fiscalizaciones que exigen cosas del siglo pasado" (Participante 48).

b) Evaluativa. El concepto de vocación docente es presentado para determinar si un profesor es bueno o malo en sus labores profesionales: "Sirve para clasificar a los buenos profesores de los malos" (Participante 163).

\section{UTILIDAD PERSONAL DE LA VOCACIÓN DOCENTE}

Dos de las categorías construidas para clasificar las respuestas comparten la característica de asociar la utilidad de la vocación a un campo individual y/o personal.

a) Justificación interna y personal. La vocación docente se utiliza para autoevaluar el desempeño laboral y justificar la elección de la carrera profesional: "No es algo que sea del campo de lo útil, sino de una toma de conciencia" (Participante 170).

b) Cambio social. La vocación docente sirve para promover cambios en la sociedad: "Es lo que impulsa el día a día del docente, es desde ahí de donde debe nacer la necesidad de generar cambios en la sociedad" (Participante 18).

c) Sin utilidad. Una de las categorías construidas para clasificar las respuestas no logra determinar alguna utilidad a la vocación docente: "Es que útil no creo que sea" (Participante 135). 
REVISTA SABERES EDUCATIVOS, Nº 5, JULIO-DICIEMBRE 2020

\section{Tabla 5}

Respuestas a la pregunta ¿Qué utilidad tiene la vocación docente?

\begin{tabular}{lccc}
\hline \multicolumn{1}{c}{ Macrocategorias } & Categorías & Frecuencia & Porcentaje \\
\hline Utilidad laboral de la vocación & Esclavitud laboral. & 14 & $10,9 \%$ \\
docente & Evaluativa & 28 & $21,9 \%$ \\
& Justificación interna y & 73 & $57 \%$ \\
Utilidad personal de la & personal. & & \\
vocación docente & Cambio social & 7 & $5,5 \%$ \\
& Sin utilidad & 6 & $4,7 \%$ \\
Sin Utilidad & & $\mathbf{1 2 8}$ & $\mathbf{1 0 0 \%}$ \\
Total respuestas & & & \\
\hline
\end{tabular}

\section{Grupos focales}

\section{¿Qué es la vocación docente?}

Para los participantes de los grupos focales, el concepto de vocación docente tiene múltiples interpretaciones, las cuales van a estar influidas por diferentes variables. Sin embargo, se puede declarar que casi la mayoría coincide en que el concepto es "algo" que no se logra reconocer con claridad en sí mismo, pero que operaría cotidianamente en ellos: "Eso me suena a mí como un motivo o a ese algo que me impulsó a estudiar eso" (Participante 1, párrafo 51, grupo focal II).

Las personas consultadas reconocen ese "algo" de distintas maneras:

a) Como una motivación: "Para mí la vocación docente es... lo que me mueve... lo que me mueve hacer algo" (Participante 2, párrafo 18, grupo focal III).

b) Como ganas: "La vocación docente son las ganas de querer hacer clases" (Participante 1, párrafo 2, grupo focal II). 
c) Como decisión: "Es la razón por la que uno elige, digamos, entrar a estudiar Pedagogía" (Participante 1, párrafo 2, grupo focal II)

d) Como llamado: "Es un llamado que sentí yo a ser educadora de párvulo" (Participante 1, párrafo 7, grupo focal I).

Todas estas respuestas tienen en común el hecho de que intentan explicar el fundamento que llevó los/as estudiantes a insertarse en el mundo de la Pedagogía.

Otra característica que reconocen los/as participantes sobre ese "algo" es que la vocación docente puede o no estar presente en las personas que se relacionan con el contexto pedagógico: "Si tú no tienes esa vocación... (Participante 3, párrafo 14, grupo focal I)"; "Si yo no tuviera vocación docente, no sé qué haría en esta carrera, la verdad" (Participante 1, párrafo 7, grupo focal I).

\section{¿Cómo surge la vocación docente?}

A diferencia de lo planteado en el punto anterior, existen más puntos de encuentro respecto al origen de la vocación docente. Las respuestas pueden organizarse en el esquema que se presenta a continuación (Figura 1), el cual proponemos llamar "Ciclo vital de la vocación docente".

"Puede que ahí haya nacido la vocación, en esa primera parte, ese primer, esa primera parte la vocación docente y después se haya desarrollado, se haya construido y reafirmado, y puede ser una forma particular, pero como un ejemplo, no como a todas las personas que estudian educación les tiene que pasar eso" (Participante1, párrafo 53 , grupo focal II). 


\section{Figura 1}

Ciclo vital de la vocación docente

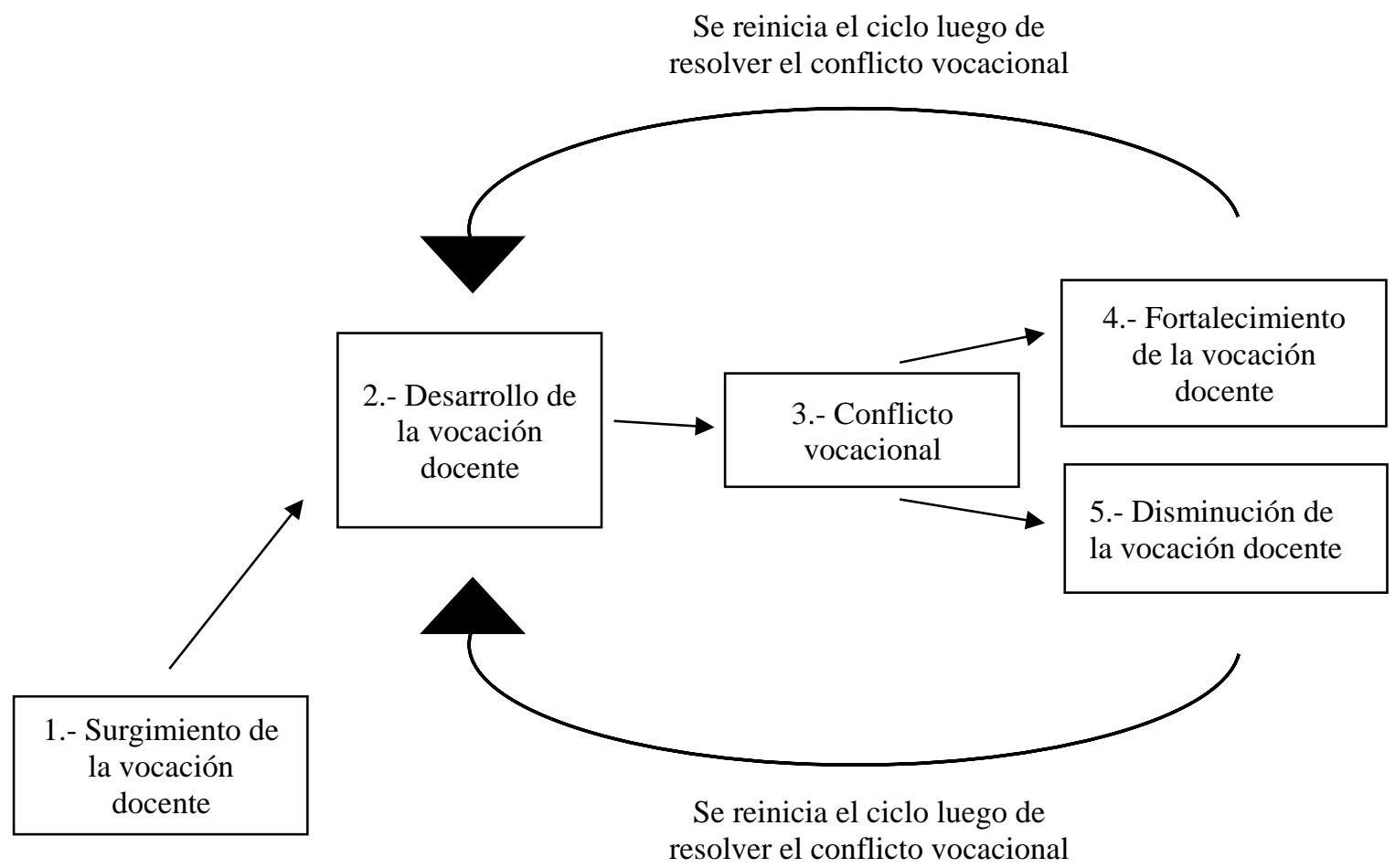

\section{SURGIMIENTO DE LA VOCACIÓN DOCENTE}

El surgimiento de la vocación docente constituye el primer hito del "Ciclo vital de la vocación docente" y corresponde al momento en que la persona se hace consciente de dicha vocación, pudiendo operar desde ella. Este momento se puede originar de diferentes formas:

a) A través de un llamado interior, donde la persona reconoce un "algo" o un "eso" que la moviliza a seguir una trayectoria de vida ligada a la educación: "Es un llamado que sentí, desde muy pequeña" (Participante 1, párrafo 30, grupo focal I).

b) A partir de la relación directa con un modelo docente o familiar significativo: "Yo creo que una es teniendo buenos referentes de docentes, o sea nadie llega a querer ser profesor solo teniendo malos profesores, al menos tiene que haber un profesor que haya marcado 
positivamente... que haya hecho muy bien su trabajo" (Participante 2, párrafo 61, grupo focal I)

c) A partir de la determinación de un camino a seguir en la proyección que hacen las personas en torno a su futuro laboral: "La vocación [docente] es el camino que tú deseas" (Participante 1, párrafo 3, grupo focal III).

d) Puede tener un origen desconocido: "No sé por qué nació, simplemente nació, como querer enseñar a los demás" (Participante 3, párrafo 71, grupo focal I).

\section{DESARROLLO DE LA VOCACIÓN DOCENTE}

El segundo momento del ciclo tiene relación con la forma en que algunas variables, tanto internas como externas, van a permitir que se desarrolle o no la vocación en los estudiantes de Pedagogía,

Para los/as estudiantes de Pedagogía, los elementos internos serían los siguientes:

a) Expectativas de la persona en relación a lo que esperaba encontrar o alcanzar ingresando a la carrera de Pedagogía: "Si tus expectativas son muy altas y vas... y de verdad no te gusta, tu vocación se ve afectada de manera negativa" (Participante 3, párrafo 27, grupo focal II).

b) La motivación o ese "algo" que moviliza a las personas a realizar su trabajo: "Conozco profesores que al principio les gustaba mucho la carrera, estaban muy motivados, hacían clases bacanes" (Participante 3, párrafo 27, grupo focal II).

Por otra parte, en opinión de los/as encuestados/as, los elementos externos serían los siguientes:

a) El contexto en el que se van a desenvolver en su futuro laboral, cuando estén titulados/as:

"Quiero trabajar en contextos que tengan índices de vulnerabilidad... pero hay algo que tiene relación con la calidad del trabajo y la cantidad de niños que hay por sala, y el salario, finalmente, que te ofrecen, porque personalmente estos contextos están muy lejos de mi casa y el sueldo que me ofrecen es bajo para la distancia que hay, entonces ¿qué pasa con mi vocación docente?... Mi vocación docente sí se ve afectada". (Participante 3, párrafo 22, grupo focal I). 
b) La institución donde se estudia Pedagogía:

"Pero dentro de la propia carrera que yo también tengo habilidades como para transmitir y siento que es necesario como el transmitir un conocimiento con las estrategias necesarias que siento estoy aprendiendo en una buena universidad, entonces, se reafirmó esa como vocación” (Participante 1, párrafo 30, grupo focal II).

c) Los escenarios pedagógicos de la formación docente donde la vocación docente opera:

"Hay como etapas en las que uno va construyendo su vocación, primero es el llamado, que para mí es primero que cualquier cosa, no solo en Pedagogía o educación, ese llamado a hacer algo como la primera parte de la vocación; después estoy haciéndolo y por lo menos lo que me pasó a mí en la 'U' fue que como el primer año, sí, esto me encanta y todo y después viene la segunda parte, que es cuando uno se enfrenta a la práctica, estar frente a los niños" (Participante 2, párrafo 40, grupo focal II).

d) Las condiciones laborales docentes: "No lo voy a hacer por los sueldos, me voy a morir de hambre, entonces yo creo que ahí la vocación se ve ahogada, por las condiciones docentes que tenemos hoy día los profesores" (Participante 30, párrafo 40, grupo focal I).

e) El nivel escolar en el que se desempeñarán los futuros docentes, argumentando que en los niveles escolares que atienden a estudiantes de menor edad la vocación debe ser mayor:

"Yo creo que hay una especie de pirámide vocacional: en los niveles más bajos de edad se requieren más vocación. Es decir, yo creo que para ser educador de párvulos se requiere incluso más vocación que para ser profesor de básica, y así sucesivamente hasta la universidad" (Participante 4, párrafo 18, grupo focal I).

\section{CONFLICTO VOCACIONAL}

La tercera etapa del "Ciclo de la vocación docente" corresponde a un momento transcendental de dicho ciclo: el conflicto vocacional. Es el momento en que se evalúa la vocación docente que se desarrolla en la etapa dos. La resolución de este conflicto puede disminuir o reafirmar la vocación. Los eventos o factores que gatillan este conflicto tienen la particularidad de que pueden aparecer 
en diferentes periodos de la vida del docente. Algunos de ellos pueden ser intencionados por la misma formación docente y otros pueden ser fortuitos, como resultado de enfrentar determinadas situaciones o experiencias.

“Pero 'Práctica 3' la encuentro crucial, en la que desertan un montos de compañeras, porque se dan cuenta que no es lo suyo, porque de verdad no son capaces de hacerlo, y mucho que tienen [vocación docente] cuando ingresaron entran en crisis" (Participante 1, párrafo 66, grupo focal III).

\section{FORTALECIMIENTO DE LA VOCACIÓN DOCENTE}

Para los estudiantes de Pedagogía la vocación docente se va a potenciar cuando, al enfrentarse a un conflicto vocacional producido por un evento en particular o varios, esta se vea reafirmada, lo cual les permite seguir operando con una nueva estructura cognitiva.

"El reafirmar nuevamente esto, como después de todo lo que te enseñan en la U... y cuando uno está en la clase, este es el gran desafío, y sigo teniendo la vocación, y ahí viene como la otra parte, cuando uno lo vuelve a reafirmar, y creo que va siendo constante toda la vida, esa reafirmación... Es la decisión de uno si es que se reafirma o no" (Participante 2, párrafo 40, grupo focal II).

\section{DISMINUCIÓN DE LA VOCACIÓN DOCENTE}

Por otro lado, la resolución del conflicto también puede disminuir la vocación docente, pudiendo incluso hacerla desaparecer:

"El tema de cómo se cuida la vocación entre los mismos profesores es algo en lo que hay que ahondar más, hoy día, en la discusión frente a la docencia, como a veces los mismos profesores... Emmm, un colegio puede tener prácticas que desmotivan a los nuevos profesores... que terminan perjudicando la vocación docente" (Participante 2, párrafo 87, grupo focal I). 


\section{¿QUÉ UTILIDAD TIENE LA VOCACIÓN DOCENTE?}

Para algunos/as participantes la vocación docente les permite construir una coherencia interna en relación a su decisión de estudiar Pedagogía, nutriendo el propio discurso que explicaría el motivo para elegir esta carrera profesional en vez de otras: "Si yo no tuviera vocación docente, no sé qué haría en esta carrera la verdad, es mi base, es mi fundamento, lo fundamental -yo creo- para cualquier profesor" (Participante 1, párrafo 7, grupo focal I).

Para otros/as participantes la vocación docente es utilizada para legitimar prácticas, estereotipos y expectativas que se vinculan con el desempeño docente, es decir, configura lo que se espera del docente dentro del contexto escolar:

“Todos los comerciales de ‘Elige Educar’ y como esta imagen más, no sé cómo decirlo, una imagen, no sé si ideal, pero hay mucho discurso de cómo debería ser un profesor y, al final, como idealizar mucho la vocación docente por sobre otras" (Participante 2, párrafo 14, grupo focal II).

Para algunos/as participantes la vocación docente también permite legitimar la devaluación profesional que tienen los/as profesores/as:

"Pero además creo que, en general, la carrera de Pedagogía tiene muy poco, muy pocas retribuciones, de otro, de otras formas que no sea como la emocional; entonces, claro, es una carrera mal pagada, como... Entonces, ¿qué necesitamos los profesores para estudiar?: vocación” (Participante 1, párrafo 15, grupo focal II).

\section{Discusión y conclusiones}

Como primera característica de las representaciones sociales que están a la base de los participantes de esta investigación, se puede asignar la propiedad de entidad a la vocación docente. Esto significa que se le atribuye la cualidad de ser algo que existe en esencia o que da forma a una cosa (RAE, 2001), pero la gran mayoría no logra describir qué es con exactitud ese "algo" que comprenden como vocación. A la vez, ese "algo" puede estar presente en la vida de una persona, ya sea que surja de forma innata, como se plantea en la teoría factorialista de Fingermann (1968, 
REPRESENTACIONES SOCIALES DE LA VOCACIÓN DOCENTE / CELIS-IBÁÑEZ; SEBASTIÁN-BALMACEDA

citado en González, 2003), o desarrollada individualmente (Super, 1968, citado en González, 2003), lo que produce que en el discurso individual se hable de "tener" o "no tener" vocación.

En consecuencia, desde la formación inicial docente se podría trabajar la desencialización del concepto de vocación docente como factor fijo y estable, porque podría generar limitaciones en el desarrollo pedagógico de los estudiantes, haciendo un paralelo con Dweck (1999) y su teoría de la inteligencia fija, buscando construir en ellos una concepción más dinámica de la vocación docente.

Como segunda característica de las representaciones sociales, se reconoce en la gran mayoría de los casos una permanente construcción, a través de procesos dinámicos explicados en el "Ciclo vital de la vocación docente", coincidiendo con lo que plantean Vaillant (2007) y Ávalos (2012), respecto a que la vocación docente, como dimensión afectiva de la identidad docente, se desarrolla a lo largo de toda la vida, considerando diferentes etapas, personales y sociales. Sin embargo, es importante señalar que existe un grupo minoritario que hace referencia a que la vocación docente sería solo de carácter individual, sin influencia del entorno, lo que se podría explicar desde Zambrano (2014), Gracia (2007), Dewck (1999) y Larrosa (2010), como una representación social innata, sin posibilidad de vivenciar el "Ciclo de la vocación docente" en forma vincular de sus etapas, sino de forma aislada.

El desarrollo humano se caracteriza por ser dinámico, por lo que es lógico pensar que la vocación docente es algo dinámico también, que evoluciona en el tiempo y que no surge solo en un momento determinado de la vida de un individuo, sino que existe la posibilidad de construirla en diferentes periodos. Sin embargo, surge la interrogante sobre cómo los programas de formación de profesores pueden intencionar el desarrollo de la vocación docente, para que sea un aporte al futuro ejercicio de la profesión y no una limitante para el sistema educacional.

Como tercera característica de las representaciones sociales, se desprende que esta entidad de vocación docente posee intrínsecamente una idea de motivación que moviliza a los/as profesores/as, determinando su identidad profesional, tal como lo plantean Bolívar y Domingo (2006), Nuñez (2004) y Hargreaves (1999), citados en Rodríguez y Villalón (2016).

Como cuarto punto en común que se manifiesta en ambos instrumentos, está la utilidad que se le otorga a la vocación docente para explicar diferentes fenómenos y crear su propio significado (Moscocivi, 2001, citado en Carretero y Castorina, 2010). Esta característica movilizaría en mayor 
o menor grado hacia el quehacer profesional, además de crear una narrativa personal, sustentada en una narrativa maestra que está en la base de los discursos docentes (Hammack, 2008). Así, por ejemplo, la vocación docente explicaría la decisión de estudiar Pedagogía por sobre otras carreras profesionales o permitiría tolerar un bajo sueldo por la satisfacción que implica poner en práctica dicha vocación.

Por último, en diversas opiniones recogidas en este estudio se constata la percepción de un carácter heroico que tendría la vocación docente, debido al aporte que realizaría a la sociedad. Ello podría generar altas expectativas en torno al futuro desempeño laboral, las cuales no siempre se pueden mantener en el tiempo, por lo que el desarrollo emocional o afectivo de los docentes debería ser parte también de los programas de formación de profesores.

Es importante resaltar que en el cuestionario se evidenciaron algunos puntos de vista que enmarcan la vocación docente como un factor sin una utilidad importante, como algo que esclaviza e incluso limita el trabajo docente, por lo que su uso o comprensión no sería necesario para desempeñar una buena labor. Lo más significativo para desenvolverse de forma profesional vendría dado por otros factores, tales como la confianza en el propio trabajo, la autovaloración (Venegas, 2002), la motivación y el involucramiento afectivo (Sebastián, Gallardo y Calderón, 2016). Estos puntos de vista se pueden relacionar con una vocación docente que no es trascendental a la hora de realizar una clase, enmarcando en lo técnico-profesional el buen desempeño del ejercicio docente. Sin embargo, también se involucran otras variables de carácter afectivas o emocionales, por lo que existe la posibilidad de que lo que algunos/as están entendiendo por vocación docente para otros/as sea motivación, involucramiento o algún otro concepto, pero que por las características de este estudio no es posible determinar.

Finalmente, como demuestran los resultados obtenidos, es destacable que para la gran mayoría de los/as participantes la vocación docente sea un factor fundamental en sus vidas o que la consideren necesaria para desempeñarse como profesores/as. Lo anterior se puede relacionar con la representación social que permite al colectivo de los profesores operar desde un pensamiento común, donde sería crucial valorar y destacar la vocación docente como una característica propia del gremio (Carretero y Castorina, 2010). Sin embargo, es importante destacar que también existen voces disidentes frente a este planteamiento, las cuales se expresaron en los cuestionarios, 
REPRESENTACIONES SOCIALES DE LA VOCACIÓN DOCENTE / CELIS-IBÁÑEZ; SEBASTIÁN-BALMACEDA

atribuyendo poca o nula trascendencia a la vocación docente. Estas voces no participaron en los grupos focales, lo que habría sido muy interesante para profundizar en esta perspectiva

\section{Referencias}

Álvarez-Espinoza, A. \& Sebastián, C. (2018). El concepto dialéctico de internalización en Vygotski: aproximaciones a un debate. Psicología, Conocimiento y Sociedad, 8(1).

Ávalos, B. (2012). Cómo ven su identidad los docentes chilenos. Revista Perspectiva Educacional, $(51)$, 77-95. Recuperado de http://www.perspectivaeducacional.cl/index.php/peducacional/article/viewFile/74/32

Calderón, M. (2017). Profesor/a universitario/a: sentido del trabajo docente en la construcción de una identidad académica/profesional [Tesis doctoral no publicada], Pontificia Universidad Católica de Chile.

Carretero, M y Castorina, J. (2010). La construcción del conocimiento histórico: enseñanza, narración e identidades. Paidós.

Dweck, C. (1999). Self-theories. Their Role in Motivation, Personality, and Development. Psychology Press.

Fuentes, T. (2001). La vocación docente: una experiencia vital. Ars Brevis, (7), 285-303. http://dx.doi.org/2339-9775

González, V. (2003). La orientación profesional desde la perspectiva histórico-cultural del desarrollo humano. Revista Cubana de Psicología, (20), 260-268.

Gracia, D. (2007). La vocación docente. Anuario Jurídico y Económico Escurialense, (40), 807816. Recuperado de http://www.rcumariacristina.com/wp-content/uploads/2010/12/IVDIEGO-GRACIA.pdf 
REVISTA SABERES EDUCATIVOS, Nº 5, JULIO-DICIEMBRE 2020

Grund, A., Brassler, N., \& Fries, S. (2016). The Long Arm of Work: A Motivational Conflict Perspective on Teacher Strain. Teaching and teacher education, (60), 153-163. https://doi.org/10.1016/j.tate.2016.08.013

Hammack, P. (2008). Narrative and the Cultural Psychology of Identity. Personality and Social Psychology Review, 12(3), 222-247. https://doi.org/10.1177/1088868308316892

Hamui-Sutton, A. \& Varela, M. (2013). La técnica de grupos focales. Investigación en Educación Médica, 2(1), 55-60. Recuperado de http://riem.facmed.unam.mx/sites/all/archivos/V2Num01/09_MI_HAMUI.PDF

Larrosa, F. (2010). Vocación docente versus profesión docente en las organizaciones educativas. Revista Electrónica Interuniversitaria de Formación del Profesorado, (13), 43-51. Recuperado de http://www.aufop.com/aufop/uploaded_files/articulos/1291992517.pdf

Marchesi, A. y Díaz, T. (2007). Las emociones y los valores del profesorado. Fundación SM. Recuperado de http://www.oei.es/valores2/Lasemocionesprofesorado.pdf

Morgade, G. (3-5 de julio de 2008). Trabajo docente y relaciones de género: aportes conceptuales y epistemológicos de la investigación en torno a la construcción social del cuerpo sexuado [Ponencia]. VII Seminario Redestrado "Nuevas regulaciones en América Latina”, Buenos Aires, Argentina. Recuperado de http://www.fae.ufmg.br/estrado/cdrom_seminario_2008/textos/ponencias/Ponencia\%20G raciela\%20Morgade.pdf

Real Academia Española. (2001). Diccionario de la lengua española (22a ed.). Recuperado en mayo $2020 \mathrm{de}$ http://lema.rae.es/drae2001/srv/search?id=4tTO47LEcDXX2ShuJVtn

Rodríguez, P. y Villalón, M. (2016). Lidiando con la tensión: conflictos en la identidad profesional de docentes en Chile. Paideia, (59), 35-56. Recuperado de http://revistas.udec.cl/index.php/paideia/article/view/692

Sebastián, C., Gallardo, G. y Calderón, M. (2016). Sentido identitario de la formación. Una propuesta para articular el desarrollo de la identidad y el aprendizaje en contextos 
REPRESENTACIONES SOCIALES DE LA VOCACIÓN DOCENTE / CELIS-IBÁÑEZ; SEBASTIÁN-BALMACEDA

educativos. Papeles de trabajo sobre cultura, educación y desarrollo humano, 12(3), 412. Recuperado de https://dialnet.unirioja.es/servlet/articulo?codigo=5795130

Vaillant, D. (5-7 septiembre de 2007). La identidad docente [Ponencia]. I Congreso Internacional "Nuevas tendencias en la formación permanente del profesorado", Barcelona, España. Recuperado de http://www.ub.edu/obipd/docs/la_identidad_docente_vaillant_d.pdf.

Venegas, P. (2002). Identidad profesional, discurso y proceso de formación. PIIE.

Zambrano, M. (2014). Educación para la democracia. Bajo Palabra, Revista de Filosofía, (9), 155163. Recuperado de https://revistas.uam.es/bajopalabra/article/view/86 